\title{
CORRIGENDUM
}

\section{Consensus meeting: monosodium glutamate - an update}

\author{
K Beyreuther, HK Biesalski, JD Fernstrom, P Grimm, WP Hammes, U Heinemann, O Kempski, \\ P Stehle, H Steinhart and R Walker
}

European Journal of Clinical Nutrition (2007) 61, 928; doi:10.1038/sj.ejcn.1602775

Correction to: European Journal of Clinical Nutrition (2007) 61, 304-313. doi:10.1038/sj.ejcn.1602526

Since the publication of this issue, the authors have identified errors in the abstract and in the last paragraph of page 307. One figure is incorrect. The correct abstract and paragraph are printed below.

Conclusion: Total intake of glutamate from food in European countries is generally stable and ranged from 5 to $12 \mathrm{~g} /$ day (free: ca. $1 \mathrm{~g}$, protein-bound: ca. $10 \mathrm{~g}$, added as flavor: ca. $0.4 \mathrm{~g}$ ). L-Glutamate (GLU) from all sources is mainly used as energy fuel in enterocytes. A maximum intake of $6.000 \mathrm{mg} / \mathrm{kg}$ body weight is regarded as safe. The general use of glutamate salts (monosodium-L-glutamate and others) as food additive can, thus, be regarded as harmless for the whole population. Even in unphysiologically high doses GLU will not trespass into fetal circulation. Further research work should, however, be done concerning the effects of high doses of a bolus supply at presence of an impaired blood brain barrier function. In situations with decreased appetite (e.g., elderly persons) palatability can be improved by low dose use of monosodium-L-glutamate.

Can we define a safe level of intake regarding added GLU?

Consensus. Based on dietary animal studies (metabolic control), a NOAEL of $6000 \mathrm{mg} / \mathrm{kg}$ body weight was calculated in weaning animals, on parenteral supply $500-1000 \mathrm{mg} / \mathrm{kg}$ body weight.

The authors would like to apologize for the error and any inconvenience this may have caused. 